\title{
Study the Extent of The Relationship Among Hormonal Disturbance, Vitamin D Deficiency and Age in Women with Polycystic Ovary Thiqar City, Southern Iraq
}

\author{
Shalan H. Al-Saedy ${ }^{1}$, Ali E. Al-Snafi ${ }^{2 *}$, Mahdi M. Thuwaini ${ }^{3}$ \\ \{aboahmad61@yahoo.com ${ }^{1}$,dr.aliasm@utq.edu.iq ${ }^{2}$ \} \\ College of Medical and Healthy Techniques, Southern Technical University- Basrah ${ }^{1,3}$ \\ College of Medicine, University of Thi-Qar- Iraq ${ }^{2}$
}

\begin{abstract}
The goal of this study was to see if there was a link between LH, FSH, testosterone, oestradiol, progesterone, and metabolic markers, including AMH and vitamin $\mathrm{D}$, in a woman.. PCOS patients had significant increases in serum levels of LH (P <0.01), FSH $(\mathrm{P} 0.05), \mathrm{LH} / \mathrm{FSH}$ ratio $(\mathrm{P}<0.05)$, testosterone $(\mathrm{P}<0.01)$, progesterone $(\mathrm{P}<0.05)$, antimalaria $(\mathrm{P}<0.001)$, glucose $(\mathrm{P}<0.01)$, total cholesterol $(\mathrm{P} 0.01)$, triglycerides $(\mathrm{P}$ $<0.001)$, LDL ( $\mathrm{P}<0.01)$, VLDL $(\mathrm{P}<0.05)$, and Vitamin D ( $<<0.01)$. AMH appeared to be favourably connected with higher levels of LH, FSH, LH/FSH ratio, testosterone, progesterone, hyperglycemia, total cholesterol, triglycerides, LDL, and VLDL, and uncorrelated with oestradiol and HDL. We can conclude that AMH can potentially be applicate as a diagnostic marker for PCOS, the results also showed vitamin D deficiency is related to pathophysiology of PCOS. Vitamin D serum levels showed an inverse correlation with hyperglycaemia, hyperlipidaemia, and hormonal disturbances in PCOS.
\end{abstract}

Keywords: Hormonal disorders, metabolic disorders, PCOS, Vitamin D, AMH

\section{Introduction}

PCOS is a complicated endocrine condition that affects women of reproductive age and is thought to be the leading cause of infertility due to anovulation. [1-2]. It has been described as a syndrome characterised by oligomenorrhea and polycystic ovaries, as well as hirsutism, acne, and obesity [3]. Excess secretion of androgen associated with changes in ovarian morphology represented the main pathological factor in PCOS. Hyperlipidaemia, insulin resistance, and psychosocial dysfunction are part of the symptoms and signs of PCOS [4]. PCOS is diagnosed by the presence of oligo amenorrhoea, polycystic ovaries morphology, and hyperandrogenaemia [5].

Anti-Mullerian hormone (AMH), a glycoprotein secreted by the granulosa cells of ovarian early developing follicles, has also been used in the diagnosis of PCOS [6]. PCOS is defined by an overabundance of tiny antral follicles in the ovaries and high levels of AMH in the blood [7]. Vitamin D insufficiency is frequent among women with PCOS, according to numerous research [8]. Low vitamin D levels were linked to menstrual abnormalities, ovulation issues, and 
infertility [9-10]. Vitamin D insufficiency has also been linked to increased insulin resistance and and other factors [10-11]. Vitamin D receptors were found in a variety of human tissues, including the ovary and endometrial, indicating that vitamin D plays an active function in female reproductive organs [12-13]. The researchers wanted to see if there was a link of serum vitamin D levels, hormonal irregularities, and age in individuals with PCOS.

\section{Materials and Methods}

Fasting of 60 blood samples were composed from married infertile women (20-40 years) with PCO attending Al-Shatra hospital, Bint AL-Hoda, and Al-Hussein teaching hospital in Thi-Qar governorate- Iraq, who diagnosed by gynaecologists, through the period from 1 September 2020 until the end of November 2020. Patients with androgen-secreting tumours, hyperprolactinemia, The study excluded women with Cushing syndrome, congenital adrenal hyperplasia, contraceptives, hypoglycemic drugs, lipid-lowering therapy, or hormonal prescriptions. To serve as a control, fasting blood samples were taken from 30 healthy nonpregnant women of similar ages. The study was permitted by Thi-Qar governorate's health directorate and the South technical university's ethical board. All participants gave their informed consent. Glucose and lipid profile were determined by using Cobas C311 photometric assays and ion-selective electrode measurements (Kits and instrument Roche- Germany), while, LH, FSH, oestradiol, progesterone, testosterone, AMH, and vitamin D were determined by using Cobas 411 immunoassay analysis (Kits and instrument Roche- Germany) [14-15]. All data is presented as a mean \pm SE. Student t-tests were used to analyse differences in mean values for specific hormone measures.

\section{Results}

In the group aged 20-25 years, PCO patients showed significantly elevated serum levels. While the serum level of oestradiol, HDL cholesterol, and vitamin D were significantly declined. Table 1 shows vitamin D levels were positively connected with oestradiol and HDL cholesterol while being negatively correlated with $\mathrm{LH}, \mathrm{FSH}, \mathrm{LH} / \mathrm{FSH}$ ratio, total testosterone, progesterone, AMH, hyperglycemia, total cholesterol, triglycerides, and VLDL cholesterol. 
Table 1: Data in PCOS patients aged 20-25 years in comparison with aged-matched control.

\begin{tabular}{|c|c|c|c|c|}
\hline \multicolumn{2}{|c|}{ Parameter studied } & Control (15) & PCOS patients (37) & Significancy \\
\hline \multicolumn{2}{|c|}{ LH (IU/L) } & $4.99 \pm 0.62$ & $15.86 \pm 0.96$ & $\mathrm{P}<0.001$ \\
\hline \multicolumn{2}{|c|}{ FSH (IU/L) } & $3.42 \pm 0.32$ & $4.68 \pm 0.45$ & $P<0.05$ \\
\hline \multicolumn{2}{|c|}{ LH/FSH } & $1.45 \pm 0.08$ & $3.38 \pm 0.12$ & $\mathrm{P}<0.05$ \\
\hline \multicolumn{2}{|c|}{ Total testosterone (ng/ml) } & $0.46 \pm 0.08$ & $0.58 \pm 0.06$ & $\mathrm{P}<0.05$ \\
\hline \multicolumn{2}{|c|}{ Oestradiol (pmol/l) } & $116.64 \pm 8.62$ & $106.33 \pm 9.32$ & $\mathrm{P}<0.05$ \\
\hline \multicolumn{2}{|c|}{ Progesterone (nmol/ml) } & $0.67 \pm 0.06$ & $1.44 \pm 0.09$ & $P<0.05$ \\
\hline \multicolumn{2}{|c|}{$\overline{A M H}(\mathbf{n g} / \mathbf{m l})$} & $2.40 \pm 0.12$ & $10.00 \pm 0.23$ & $P<0.001$ \\
\hline \multicolumn{2}{|c|}{ Glucose (mg/dl) } & $94.60 \pm 3.23$ & $109.02 \pm 4.32$ & $P<0.05$ \\
\hline \multirow{5}{*}{$\begin{array}{l}\text { Lipid } \\
\text { profile }\end{array}$} & Total cholesterol (mg/dl) & $170.00 \pm 6.16$ & $176.00 \pm 7.22$ & $\mathrm{P}<0.05$ \\
\hline & Triglycerides (mg/dl) & $150.66 \pm 5.56$ & $175.81 \pm 6.32$ & $P<0.01$ \\
\hline & LDL (mg/dl) & $98.81 \pm 3.51$ & $97.17 \pm 4.12$ & NS \\
\hline & VLDL (mg/dl) & $30.76 \pm 1.45$ & $35.18 \pm 1.94$ & $\mathrm{P}<0.05$ \\
\hline & HDL (mg/dl) & $48.93 \pm 1.66$ & $45.91 \pm 1.57$ & $\mathrm{P}<0.05$ \\
\hline \multicolumn{2}{|c|}{ Vitamin D (ng/ml) } & $16.95 \pm 0.96$ & $14.26 \pm 0.84$ & $\mathrm{P}<0.05$ \\
\hline
\end{tabular}

In the group aged 26-30 years, serum biochemical analysis of $\mathrm{PCO}$ patients revealed significant elevation of serum levels were illustrated. While the serum level were significantly declined in comparison with control. As indicated in Table 2, vitamin D levels were positively connected with oestradiol testosterone and HDL cholesterol, but negatively correlated with LH, FSH, $\mathrm{LH} / \mathrm{FSH}$, total testosterone, AMH, hyperglycemia and etc. 
Table 2: Similar to Table 1 but for patients aged 26-30 years.

\begin{tabular}{|c|c|c|c|c|}
\hline \multicolumn{2}{|c|}{ Parameter studied } & Control (6) & PCOS patients (11) & Significancy \\
\hline \multicolumn{2}{|c|}{ LH (IU/L) } & $5.67 \pm$ & $9.58 \pm$ & $\mathrm{P}<0.01$ \\
\hline \multicolumn{2}{|c|}{ FSH (IU/L) } & $3.79 \pm$ & 5.37 & $\mathrm{P}<0.05$ \\
\hline \multicolumn{2}{|c|}{ LH/FSH } & $1.49 \pm$ & $1.78 \pm$ & $\mathrm{P}<0.05$ \\
\hline \multicolumn{2}{|c|}{ Total testosterone (ng/ml) } & $0.42 \pm$ & $0.48 \pm$ & $\mathrm{P}<0.05$ \\
\hline \multicolumn{2}{|c|}{ Oestradiol (pmol/l) } & $107.90 \pm$ & $74.33 \pm$ & $\mathrm{P}<0.05$ \\
\hline \multicolumn{2}{|c|}{ Progesterone $(\mathrm{nmol} / \mathrm{ml})$} & $0.84 \pm$ & $0.76 \pm$ & NS \\
\hline \multicolumn{2}{|c|}{ AMH(ng/ml) } & $5.35 \pm$ & $8.96 \pm$ & $P<0.01$ \\
\hline \multicolumn{2}{|c|}{ Glucose (mg/dl) } & $97.80 \pm$ & $101.00 \pm$ & $\mathrm{P}<0.05$ \\
\hline \multirow{5}{*}{$\begin{array}{l}\text { Lipid } \\
\text { profile }\end{array}$} & Total cholesterol (mg/dl) & $190.00 \pm$ & $196.00 \pm$ & $\mathrm{P}<0.05$ \\
\hline & Triglycerides (mg/dl) & $184.00 \pm$ & $211.50 \pm$ & $\mathrm{P}<0.01$ \\
\hline & LDL (mg/dl) & $91.00 \pm$ & $99.70 \pm$ & $\mathrm{P}<0.05$ \\
\hline & VLDL (mg/dl) & $41.20 \pm$ & $45.60 \pm$ & $\mathrm{P}<0.05$ \\
\hline & HDL (mg/dl) & $53.80 \pm$ & $40.72 \pm$ & $\mathrm{P}<0.01$ \\
\hline \multicolumn{2}{|c|}{ Vitamin D (ng/ml) } & $21.96 \pm$ & $17.28 \pm$ & $\mathrm{P}<0.05$ \\
\hline
\end{tabular}

In PCO non-control aged 31-35 years, serum levels of LH were considerably higher. Serum levels of oestradiol were significantly lower in the experimental group than in the control group. Vitamin D levels were positively related to oestradiol and HDL cholesterol, but negatively related to LH, FSH, LH/FSH, as indicated in Table 3. 
Table 3: Similar to Table 1 but for patients aged 31-35 years.

\begin{tabular}{|c|c|c|c|c|}
\hline \multicolumn{2}{|r|}{ Parameter studied } & Control (5) & PCOS patients (7) & Significancy \\
\hline \multicolumn{2}{|c|}{ LH (IU/L) } & $4.13 \pm 0.31$ & $11.17 \pm 0.73$ & $\mathrm{P}<0.001$ \\
\hline \multicolumn{2}{|c|}{$\begin{array}{l}\text { FSH (IU } \\
/ \mathrm{L})\end{array}$} & $3.44 \pm 0.05$ & $4.71 \pm 0.08$ & $\mathrm{P}<0.05$ \\
\hline \multicolumn{2}{|c|}{ LH/FSH } & $1.20 \pm 0.05$ & $2.37 \pm 0.06$ & $\mathrm{P}<0.01$ \\
\hline \multicolumn{2}{|c|}{ Total testosterone (ng/ml) } & $0.47 \pm 0.02$ & $0.55 \pm 0.03$ & $\mathrm{P}<0.05$ \\
\hline \multicolumn{2}{|c|}{ Oestradiol (pmol/l) } & $119.32 \pm 4.62$ & $90.39 \pm 3.78$ & $\mathrm{P}<0.05$ \\
\hline \multicolumn{2}{|c|}{ Progesterone (nmol/ml) } & $0.37 \pm 0.03$ & $0.54 \pm 0.04$ & $\mathrm{P}<0.05$ \\
\hline \multicolumn{2}{|c|}{ AMH(ng/ml) } & $2.41 \pm 0.07$ & $11.27 \pm 0.26$ & $\mathrm{P}<0.001$ \\
\hline \multicolumn{2}{|c|}{ Glucose (mg/dl) } & $82.00 \pm 3.54$ & $113.857 \pm 6.23$ & $\mathrm{P}<0.05$ \\
\hline \multirow{5}{*}{$\begin{array}{l}\text { Lipid } \\
\text { profile }\end{array}$} & Total cholesterol (mg/dl) & $198.00 \pm 7.82$ & $205.00 \pm 9.63$ & $\mathrm{P}<0.05$ \\
\hline & Triglycerides (mg/dl) & $200.00 \pm 8.82$ & $257.85 \pm 10.64$ & $\mathrm{P}<0.001$ \\
\hline & LDL (mg/dl) & $101.25 \pm 3.62$ & $105.83 \pm 3.82$ & $\mathrm{P}<0.05$ \\
\hline & VLDL (mg/dl) & $44.50 \pm 1.28$ & $56.83 \pm 1.64$ & $\mathrm{P}<0.05$ \\
\hline & HDL (mg/dl) & $58.00 \pm 2.68$ & $42.00 \pm 1.98$ & $\mathrm{P}<0.01$ \\
\hline \multicolumn{2}{|c|}{ Vitamin D (ng/ml) } & $20.51 \pm 2.82$ & $14.96 \pm 1.64$ & $\mathrm{P}<0.01$ \\
\hline
\end{tabular}

PCO patients aged 31-35 years had significantly higher serum levels when compared to the control group. The serum levels of oestradiol, on the other hand, all decreased significantly. Vitamin D levels were linked with oestradiol and HDL cholesterol, but adversely associated with LH, FSH, LH/FSH, total testosterone, AMH, hyperglycemia, total cholesterol, triglycerides, and LDL cholesterol, as indicated in Table 4. 
Table 4: Similar to Table 1 but for patients aged 36-40 years.

\begin{tabular}{|c|c|c|c|c|}
\hline \multicolumn{2}{|c|}{ Parameter studied } & Control (4) & PCOS patients (5) & Significancy \\
\hline \multicolumn{2}{|c|}{$\overline{L H}(\mathrm{IU} / \mathrm{L})$} & $6.54 \pm 0.42$ & $10.32 \pm 0.85$ & $\mathrm{P}<0.01$ \\
\hline \multicolumn{2}{|c|}{ FSH (IU/L) } & $4.40 \pm 0.12$ & $5.28 \pm 0.24$ & $\mathrm{P}<0.05$ \\
\hline \multicolumn{2}{|c|}{ LH/FSH } & $1.48 \pm 0.12$ & $2.03 \pm 0.15$ & $\mathrm{P}<0.05$ \\
\hline \multicolumn{2}{|c|}{ Total testosterone (ng/ml) } & $0.52 \pm 0.06$ & $0.68 \pm 0.08$ & $\mathrm{P}<0.05$ \\
\hline \multicolumn{2}{|c|}{$\overline{\text { Oestradiol (pmol/l) }}$} & $92.00 \pm 4.62$ & $60.00 \pm 3.32$ & $\mathrm{P}<0.01$ \\
\hline \multicolumn{2}{|c|}{ Progesterone (nmol/ml) } & $0.82 \pm 0.06$ & $0.84 \pm 0.04$ & NS \\
\hline \multicolumn{2}{|c|}{$\overline{\mathrm{AMH}(\mathrm{ng} / \mathrm{ml})}$} & $1.47 \pm 0.09$ & $3.90 \pm 0.13$ & $\mathrm{P}<0.01$ \\
\hline \multicolumn{2}{|c|}{ Glucose (mg/dl) } & $104.66 \pm 4.58$ & $165.40 \pm 6.51$ & $\mathrm{P}<0.001$ \\
\hline \multirow[t]{5}{*}{$\begin{array}{l}\text { Lipid } \\
\text { profile }\end{array}$} & $\begin{array}{ll}\text { Total } & \text { cholesterol } \\
(\mathrm{mg} / \mathrm{dl})\end{array}$ & $180.00 \pm 8.72$ & $227.00 \pm 12.64$ & $\mathrm{P}<0.001$ \\
\hline & Triglycerides (mg/dl) & $156.66 \pm 8.62$ & $210.00 \pm 10.28$ & $\mathrm{P}<0.001$ \\
\hline & LDL (mg/dl) & $127.25 \pm 6.23$ & $142.20 \pm 7.52$ & $\mathrm{P}<0.01$ \\
\hline & $\overline{\text { VLDL (mg/dl) }}$ & $45.33 \pm 6.43$ & $47.25 \pm 6.67$ & NS \\
\hline & HDL (mg/dl) & $46.00 \pm 2.12$ & $42.80 \pm 1.23$ & $\mathrm{P}<0.05$ \\
\hline \multicolumn{2}{|c|}{ Vitamin D (ng/ml) } & $29.11 \pm 1.34$ & $14.84 \pm 0.98$ & $\mathrm{P}<0.01$ \\
\hline
\end{tabular}

\section{Discussion}

All tables showed that the results of all age subgroups of the control group were similar, furthermore the results of all age subgroups in PCO patients were also identical. The results agreed with many previous studies [16], [17], [18], which mentioned that there were no variations in the level of pathological markers among age groups in PCO women.

The hormonal disturbances recorded in PCOS in this study could be attributed to hypothalamic dysfunction. Hypothalamic dysfunction may be a primary or secondary cause of abnormal steroid feedback. In either case serum LH level, rises and increased levels are observed clinically in approximately $50 \%$ of PCOS women [19]. In roughly $60 \%$ of individuals with PCOS [20], the ratio between FSH and LH levels, which is ordinarily around 2 to 1 , becomes reversed and occasionally even higher ( 2 or 3 to 1 ) as a result of this derangement [20], as shown in the current study. Increased androgen production is caused by an increase in LH hormone, which is further boosted by insulin resistance associated with this disease [21]. 
The current study showed that AMH was positively correlated with the elevated LH, FSH, LH/FSH ratio, testosterone, progesterone, glucose, and lipid profile and negatively correlated with oestradiol, and HDL. While vitamin D was negatively correlated with AMH. These results agreed with many studies [22], [23], [24]. In addition, giving vitamin D tablets to PCOS patients restored their serum AMH levels [23], [24].

Vitamin D deficiency was discussed in which greater levels of total testosterone and dehydroepiandrosterone sulphate in PCOS patients [25], [26]. Deficiency was connected to higher levels of LH, FSH, LH/FSH ratio and etc.

Vitamin D receptors (VDRs) have been found in a variety of human tissues, including the ovary and endometrium, proposing vitamin D roles in female reproductive tissues [26], [27], [28]. PCOS has been associated to metabolism of calcium and phosphate, as well as low vitamin D levels [26] [29].

$25(\mathrm{OH}) \mathrm{D}$ has been identified in women with PCOS in numerous investigations, ranging from 11 to $31 \mathrm{ng} / \mathrm{ml}$, of (67-85 percent) having values below $20 \mathrm{ng} / \mathrm{ml}$. Many research [30], [31] have proven the link between vitamin D levels and excessive LH and testosterone, as well as PCOS symptoms (infertility, hirsutism, and insulin resistance).

Vitamin D helps to boost the activity of steroidogenic enzymes such 3b-HSD. The corpus luteum is formed by luteinized human granulosa cells throughout the menstrual cycle, which produces a lot of progesterone (and a few oestrogens) and causes endometrial changes such decidualization in order to sustain a pregnancy. Increased progesterone synthesis by 1,25dihydroxy vitamin D3 potentiates granulosa cell luteinization, resulting in a healthier endometrial environment [24].

In contrast, vitamin D is associated to many factors of which are common in PCOS and have been linked to ovulatory dysfunction [31], [32]. After supplementing PCOS patients with vitamin D, they showed an improvement in insulin sensitivity [33], [34].

\section{Conclusion}

Vitamin D insufficiency and PCOS pathogenesis are clearly linked, according to the research. In PCOS patients, vitamin D may play a role in the development of hormonal and metabolic problems. Furthermore, vitamin D's ovarian action may encourage its usage as an adjuvant medication in the treatment of PCOS.

\section{Ethical considerations}

The ethics committee of the Thi-Qar governorate's health directorate, as well as the ethical board of the South technical university in Iraq, gave its approval to the study.

\section{References}

1. Bellver J, Rodríguez-Tabernero L, Robles A, Muñoz E, Martínez F, Landeras J, García-Velasco J, Fontes J, Álvarez M, Álvarez C, Acevedo B; Group of interest in reproductive endocrinology (GIER) of the Spanish fertility society (SEF). Polycystic ovary syndrome throughout a woman's life. J Assist Reprod Genet 2018; 35(1):25-39.

2. de Melo AS, Dias SV, Cavalli Rde C, Cardoso VC, Bettiol H, Barbieri MA, Ferriani RA and Vieira CS. Pathogenesis of polycystic ovary syndrome: multifactorial assessment from the foetal stage to menopause. Reproduction 2015; 150(1): R11-24.

3. Azziz R and Adashi EY. Stein and Leventhal: 80 years on. Am J Obstet Gynecol 2016; 214(2):247. 
4. Macut D, Damjanovic S, Panidis D, Spanos N, Glisic B, Petakov M, Rousso D, Kourtis A, Bjekic J and Milic N. Oxidised low-density lipoprotein concentration - early marker of an altered lipid metabolism in young women with PCOS. Eur J Endocrinol 2006;155(1):131-136.

5. Rotterdam ESHRE/ASRM-Sponsored PCOS consensus workshop group. Revised 2003 consensus on diagnostic criteria and long-term health risks related to polycystic ovary syndrome (PCOS). Hum Reprod 2004; 19(1):41-47.

6. Victoria M, Labrosse J, Krief F, Cédrin-Durnerin I, Comtet M and Grynberg M. Anti müllerian hormone: More than a biomarker of female reproductive function. J Gynecol Obstet Hum Reprod 2019; 48(1):19-24.

7. Stracquadanio M, Ciotta L, Palumbo MA. Relationship between serum anti-Mullerian hormone and intrafollicular AMH levels in PCOS women. Gynecol Endocrinol 2018; 34(3):223-228.

8. Javed Z, Papageorgiou M, Deshmukh H, Kilpatrick ES, Mann V, Corless L, Abouda G, Rigby AS, Atkin SL, Sathyapalan T. A Randomized, controlled trial of vitamin D supplementation on cardiovascular risk factors, hormones, and liver markers in women with polycystic ovary syndrome. Nutrients 2019;11(1):188.

9. Rashidi BH, Gorginzadeh M, Aalipour S, Sills ES. Age related endocrine patterns observed in polycystic ovary syndrome patients vs. ovulatory controls: descriptive data from a university based infertility center. Arch Endocrinol Metab 2016; 60(5):486-491.

10. Shalan B Al-Saedy, Mahdi M. Thuwaini, Ali E. Al-Snafi. Vitamin D, hormonal and metabolic disturbances in polycystic ovary syndrome. International Journal of Pharmaceutical Research 2021;13(2):3067-3072.

11. Rashidi H, Ghaderian SB, Moradi L. The effect of vitamin D3 on improving lipid profile, fasting glucose and insulin resistance in polycystic ovary syndrome women with vitamin D deficiency. Middle East Fertility Society Journal 2018; 23(3): 178-183.

12. Murshid RM, Abdulrazaq AA, Muhammed EM. Association between vitamin D level and polycystic ovarian syndrome in premenopausal Iraqi women. Indian Journal of Public Health Research \& Development 2019; 10(2): 698.

13. Ngo DT, Chan WP, Rajendran S, Heresztyn T, Amarasekera A, Sverdlov AL, O'Loughlin PD, Morris HA, Chirkov YY, Norman RJ, Horowitz JD. Determinants of insulin responsiveness in young women: impact of polycystic ovarian syndrome, nitric oxide, and vitamin D. Nitric Oxide 2001; 25: 326-330.

14. Al-Snafi AE. Study the efficacy of anti-estrogenic drugs in the treatment of poly cystic ovary induced in female rats by estrogen valerate. World J Pharm Sci 2014; 2(4): 313-316.

15. Al Snafi AE, Al-Fartosi KG, Al-Yasiry ZQ. Study the effect of PG E1 and PGF $2 \alpha$ on male rat reproductive functions. Immun Endoc \& Metab Agents in Med Chem 2018; 18: 1-4.

16. Al-Mulhim AA, Abul-Heija AA, Al-Talib AA, Al-Turki HA and Gasim TG. Hormonal, metabolic and clinical profile of Saudi women with polycystic ovary syndrome. Saudi Journal of Medicine and Medical Sciences 2013; 1(1): 30.

17. Da Silva Feuser CS, Barbosa JS, da Silva EB, de Medeiros SF. Current insights into gonadotropic pituitary function in the polycystic ovary syndrome. Asian Pacific Journal of Reproduction 2014; 3(1): 64-70.

18. Crisosto N, de Guevara AL, Echiburú B, Maliqueo M, Cavada G, Codner E, Paez F, Sir-Petermann T. Higher luteinizing hormone levels associated with antimüllerian hormone in postmenarchal daughters of women with polycystic ovary syndrome. Fertility and Sterility 2019; 111(2): 381-388.

19. Ambiger S, Patil SB, Rekha M, Dhananjaya S. Role of leutinizing hormone LH and insulin resistance in polycystic ovarian syndrome. International Journal Reprode Contracept Obstet Gyncol 2017; 6(9): 3892-3896.

20. Saxena P, Prakash A, Nigam A, Mishra A. Polycystic ovary syndrome: Is obesity a sine qua non? A clinical, hormonal, and metabolic assessment in relation to body mass index. Indian Journal of Endocrinology and Metabolism 2012; 16(6): 996.

21. Rosenfield RL, Ehrmann DA. The pathogenesis of polycystic ovary syndrome (PCOS): the hypothesis of PCOS as functional ovarian hyperandrogenism revisited. Endocrine Reviews 2016; 37(5): 467-520.

22. Merhi Z, Doswell A, Krebs K, Cipolla M. Vitamin D alters genes involved in follicular development 
and steroidogenesis in human cumulus granulosa cells. Journal of Clinical Endocrinology \& Metabolism 2014; 99(6):1137-1145.

23. Merhi Z, Seifer DB, Weedon J, Adeyemi O, Holman S, Anastos K, Golub ET, Young M, Karim R, Greenblatt R, Minkoff H. Circulating vitamin D relationship ships with serum antimullerian hormone levels in latereproductive- age women: women's Interagency HIV Study. Fertil Steril 2012; 98: 228234.

24. Irani M, Merhi Z. Role of vitamin D in ovarian physiology and its implication in reproduction: a systematic review. Fertility and Sterility 2014; 102(2): 460-468.

25. Ostadmohammadi V, Jamilian M, Bahmani F, Asemi Z. Vitamin D and probiotic co-supplementation affects mental health, hormonal, inflammatory and oxidative stress parameters in women with polycystic ovary syndrome. Journal of Ovarian Research 2019; 12(1): 5.

26. Fang F, Ni K, Cai Y, Shang J, Zhang X, Xiong C. Effect of vitamin D supplementation on polycystic ovary syndrome: A systematic review and meta-analysis of randomized controlled trials. Complement Ther Clin Pract 2017; 26:53-60.

27. Thomson RL, Spedding S, Buckley JD. Vitamin D in the aetiology and management of polycystic ovary syndrome. Clinical Endocrinology 2012; 77(3): 343-350.

28. Hilger J, Friedel A, Herr R, Rausch T, Roos F, Wahl DA, Pierroz DD, Weber P, Hoffmann K. A systematic review of vitamin D status in populations worldwide. British Journal of Nutrition 2014; 111(1): 23-45.

29. Lin MW, Wu MH. The role of vitamin D in polycystic ovary syndrome. The Indian Journal of Medical Research 2015; 142(3): 238.

30. Li HW, Brereton RE, Anderson RA, Wallace AM, Ho CK. Vitamin D deficiency is common and associated with metabolic risk factors in patients with polycystic ovary syndrome. Metabolism 2011; 60(10): 1475-1481.

31. Yildizhan R, Kurdoglu M, Adali E, Kolusari A, Yildizhan B, Sahin HG, Kamaci M. Serum 25hydroxyvitamin D concentrations in obese and nonobese women with polycystic ovary syndrome. Arch Gynecol Obstet 2009; 280: 559-563.

32. Muscogiuri G, Policola C, Prioletta A, Gian Pio Sorice G, Mezza T Lassandro A. Low levels of 25 $(\mathrm{OH}) \mathrm{D}$ and insulin-resistance: 2 unrelated features or a cause-effect in PCOS? Clinical Nutrition 2012; 31(4): 476-480.

33. Karadag C, Yoldemir T and Yavuz DG. Effects of vitamin D supplementation on insulin sensitivity and androgen levels in vitamin-D-deficient polycystic ovary syndrome patients. J Obstet Gynaecol Res 2018; 44(2):270-277.

34. Kensara OA. Prevalence of hypovitaminosis D, and its association with hypoadiponectinemia and hyperfollistatinemia, in Saudi women with naive polycystic ovary syndrome. J Clin Transl Endocrinol 2018; 12: 20-25. 